ABDIMAS: Jurnal Pengabdian Masyarakat Universitas Merdeka Malang
Vol.6(2) May 2021, 186-195
L-ISSN: 2721-138X e-ISSN: 2548-7159
Uttp://jurnal.unmer.ac.id/index.php/jpkm

\title{
Edukasi Budidaya Sayuran dan Bunga Hias Organik pada Yayasan “Cahaya Alam” Desa Kucur Kota Malang
}

\author{
Eny Dyah Yuniwati', Umi Afdah² \\ 'Departemen Agroteknologi, '2Departemen Agribisnis, Fakultas Pertanian, Universitas Wisnuwardhana \\ Jl. Danau Sentani No. 99 Malang, 65139, Indonesia
}

\begin{abstract}
ARTICLE INFO
Received: 2020-12-05

Revised: 2021-02-20

Accepted: 2021-04-14

Keywords:

Cultivation, Education, Organic vegetables,

Ornamental flowers

ABSTRACT

Organic farming is a natural cultivation system without using chemicals. These organic vegetables and ornamental flowers are cultivated naturally by compost and using organic pesticides. The fertilizer used in this educational process is compost fermented with Local Micro Organisms or MOL, at the location of the Cahaya Alam Foundation which is located in Kucur Village, Dau District, Malang Regency. The method used is to educate about growing organic vegetables and ornamental flowers properly, with limited land conditions. The solution given was to create an effective planting medium for cultivating organic vegetables and ornamental flowers in accordance with the limited land available at the Cahaya Alam Foundation. The planting medium uses polybags, and a simple screen house for organic vegetable nurseries. The output obtained from organic farming education is to provide assistance in the cultivation of organic vegetables at the demonstration plot, construction of screen houses and simple polybags, providing counseling, mentoring and learning to solve problems in cultivating organic vegetables and ornamental flowers at the Cahaya Alam Foundation.
\end{abstract}

(C)2021 Published by University of Merdeka Malang. This is an open access article distributed under the CC BY-SA 4.0 license (https://creativecommons.org/licenses/by-sa/4.0/)

How to cite: Yuniwati, E. D., \& Afdah, U. (2021). Edukasi Budidaya Sayuran dan Bunga Hias Organik pada Yayasan "Cahaya Alam" Desa Kucur Kota Malang. Abdimas: Jurnal Pengabdian Masyarakat Universitas Merdeka Malang, 6(2), 186-195.

https://doi.org/10.26905/abdimas.v6i2.5116

\section{PENDAHULUAN}

Sistem pertanian organik sedang naik daun dan terus berkembang, hal ini disebabkan beberapa keunggulan dari pertanian organik, salah satunya sebagai pendorong bisnis, selain besarnya permintaan pasar. Pemahaman akan bahaya bahan kimia dalam jangka waktu lama mulai disadari sehingga dicari alternative bercocok tanam yang dapat menghasilkan produk yang bebas dari cemaran bahan kimia serta menjaga lingkungan yang sehat (Nasir et al., 2020).

Yayasan "Cahaya Alam" adalah salah satu pondok di Desa Kucur, Kecamatan Dau, Malang dengan keadaan lahan yang terbatas, terdiri dari pondok yayasan yang terdiri dari ibu-ibu dan anak-anak yatim. 


\section{Edukasi Budidaya Sayuran dan Bunga Hias Organik pada Yayasan “Cahaya Alam” Desa Kucur Kota Malang}

Eny Dyah Yuniwati, Umi Afdah

Di pondok yayasan ini merupakan pondok yang banyak menampung yatim piatu dari daerah timur Indonesia. Penghuni yayasan ini kurang lebih ada 40 orang berasal dari berbagai daerah antara lain kota-kota di jatim, Pasuruan, Probolinggo, Lumajang, Malang, Madura, bahkan ada yang dari Mataram, Bima, Flores, dll. Kelompok ini bergerak di bidang yang belum produktif tetapi mengarah ke ekonomi produktif, karena yayasan ini menanam sayuran, tanaman obat dan herbal, cengkeh, dan bunga hias. Bidang yang ditekuni adalah bidang kesehatan, pendidikan, pembuatan jamu, obat oles, dan pengobatan herbal. Kelompok ini bergerak di kegiatan sosial dan pendidikan, salah satunya adalah kesehatan, dan pengobatan alternatif dari tenaga alam, yaitu memanfaatkan tumbuh-tumbuhan yang mempunyai manfaat sebagai obat kesehatan, dengan cara diracik seperti jamu. Kegiatan lain yang dilakukan adalah pendidikan untuk anak anak yatim yang ada di sana. Kebanyakan anggotanya adalah janda kurang mampu dan anak-anak yatim piatu. Ketua kelompok ini bernama Ibu Siti Sundari dan alm. Bapak Ardi. Kedua orang ini yang mempunyai keterampilan dalam pemijatan refleksi, meracik jamu dan obat oles, dan pengobatan herbal untuk berbagai penyakit.

Salah satu pendiri pondok ini mengatakan bahwa jenis makanan anak-anak masih kurang dan tidak memenuhi 4 sehat 5 sempurna karena jenis sayuran yang didapatkan sangat terbatas. Oleh karena itu, pondok sangat menunggu dermawan-dermawan yang bisa menyumbangkan bahan makanan dan sayuran. Sedangkan keinginan para santri untuk belajar bercocok tanam pertanian organik sangatlah tinggi tetapi tidak ada pengajar yang dapat memberikan pendampingan pembelajaran bercocok tanam pertanian organik yang baik dan benar. Metode penanaman pertanian dapat dilakukan dengan media polybag sebagai media tanam sayuran.

Tujuan pengabdian masyarakat ini adalah untuk memberikan pelatihan serta edukasi bercocok tanam pertanian organik pada budidaya tanaman sayuran dan bunga hias, yang dapat memberikan solusi dalam memecahkan permasalahan yang ada di lingkungan pondok yayasan "Cahaya Alam" di Desa Kucur, Kecamatan Dau, Kota Malang.

Permasalahan prioritas yang dihadapi oleh pondok Yayasan "Cahaya Alam" Desa Kucur, Kecamatan Dau, sebagai berikut: (1) Belum mengenal dan mengetahui pertanian organik; (2) Lahan yang belum dimanfaatkan oleh warga pondok yayasan "Cahaya Alam"; (3) Belum mengetahui bagaimana cara membuat pupuk organik; (4) Belum mengetahui bagaimana berbudidaya sayuran organik. Keempat permasalahan prioritas ini yang disepakati dengan Ibu Sundari, dengan harapan tim pengabdian masyarakat dapat mencarikan solusi untuk meningkatkan hasil pertanian organik bagi konsumsi warga yayasan.

Dari prioritas permasalahan di atas, beberapa solusi pemecahan masalah yang membutuhkan penyelesaian melalui program ini adalah: (1) Edukasi pertanian organik untuk tanaman sayuran. Lahan yayasan "Cahaya Alam", banyak yang ditanami tanaman sayuran dan bunga hias, maka perlu dicarikan solusi bagaimana edukasi tanaman organik diterapkan sehingga di peroleh hasil tanaman sayuran yang organik dan sehat untuk dikonsumsi. Diperlukan Pelatihan budidaya sayuran organik baik di lahan maupun di polybag dengan pembuatan mol dan pupuk organik dari limbah di sekitar yayasan "Cahaya Alam". Tanaman sayuran yang di tanam adalah sawi, selada, kacang panjang, cabai kecil, cabai besar, dan tomat. Tanaman bunga hias ditanam untuk memperindah lokasi pondok yayasan; (2) Pelatihan 
ABDIMAS: Jurnal Pengabdian Masyarakat Universitas Merdeka Malang

Volume 6, No. 2, May 2021: 186-195

pembuatan mol dan pestisida organik. Pelatihan ini diberikan untuk mendukung edukasi pertanian organik, supaya dalam bercocok tanam sayur-sayuran dapat meningkatkan kesuburan tanah dan menghindarkan dari hama dan penyakit tanaman; (3) Pemberian bantuan peralatan dan media untuk sayuran organik. Diperlukan bantuan peralatan dan media untuk pelatihan edukasi pertanian organik yaitu media tanam polybag, screen house dan pembibitan sayuran

Tujuan program untuk memberikan edukasi dan pendampingan bercocok tanam sayuran organik dalam demplot pembangunan screen house yang sederhana dan polybag, memberikan penyuluhan, pendampingan, dan pembelajaran sebagai pemecah masalah yang ada di pondok yayasan terhadap budidaya sayuran organik dan bunga hias.

\section{METODE}

Berdasarkan solusi pemecahan masalah di atas, kegiatan pengabdian di lakukan pada tanggal 21 Juni 2020, di mitra yayasan "Cahaya Alam". Jumlah mitra yayasan pondok "Cahaya alam" dan pengabdi yang terlibat pada program pengabdian ini ada 4 orang dan 2 mahasiswa. Program pengabdian ini menawarkan solusi berupa edukasi serta transfer ilmu pengetahuan dan teknologi bagi pondok yayasan "Cahaya Alam" dalam bentuk pelatihan dan pendampingan pertanian organik, pembelajaran pertanian organik, pembuatan demplot di lahan maupun demplot polybag, dan pembangunan screen house sederhana. Berikut kegiatan yang akan dilakukan.

\section{Pendidikan masyarakat}

Metode ini digunakan untuk sosialisasi program pengabdian masyarakat tentang edukasi pertanian organik, budidaya sayuran organik, budidaya tanaman toga, herbal, dan bunga hias. Kegiatan ini bertujuan untuk mengenalkan arti penting dan manfaat pertanian organik serta cara budidaya sayuran organik yang benar sekaligus menyamakan persepsi sehingga warga yayasan "Cahaya Alam" mengerti tentang arti pentingnya edukasi pertanian organik (Purba, 2016).

\section{Pelatihan}

Metode pelatihan ini digunakan untuk kegiatan yang melibatkan mitra dalam edukasi pertanian organik pada sayuran dan bunga hias yang disertai dengan demonstrasi atau percontohan untuk realisasinya.

\section{Pelatihan pembuatan MOL}

MOL (Mikro Organisme Lokal) adalah sekumpulan mikroorganisme yang bermanfaat sebagai starter dalam penguraian dan fermentasi bahan organik yang nantinya akan menjadi pupuk organik padat maupun cair. MOL yang digunakan adalah $\mathrm{MOL}$ dari nasi basi dengan bahan sebagai berikut: (1) Nasi basi 2,5 ons; (2) Air bersih 1 liter; (3) Gula pasir 5 sendok makan (Selviana, 2019). 


\section{Edukasi Budidaya Sayuran dan Bunga Hias Organik pada Yayasan “Cahaya Alam” Desa Kucur Kota Malang}

Eny Dyah Yuniwati, Umi Afdah

Langkah pembuatan $\mathrm{MOL}$ adalah sebagai berikut: (1) Kepal nasi basi hingga seukuran bola pingpong dan masukkan ke dalam kardus; (2) Tutup kardus dengan daun pisang dan tunggu hingga berjamur; (3) Siapkan larutan gula yang ditambahkan air; (4) Campurkan larutan gula dengan bola nasi yang sudah berjamur kemudian letakkan dalam wadah plastik dan diamkan selama 1 minggu; (5) MOL siap digunakan.

\section{Aplikasi MOL dalam pembuatan pupuk kompos}

Bahan yang diperlukan dalam pembuatan pupuk kompos adalah sebagai berikut: (1) Kotoran ternak 500 kg; (2) Serbuk gergaji 400 kg; (3) Arang sekam 100 kg; (4) MOL 2,5 liter; (5) air secukupnya (untuk melembabkan).

Langkah pengaplikasian MOL dalam pembuatan pupuk kompos adalah sebagai berikut: (1) Siapkan terpal atau plastik sebagai alas; (2) Taburkan kotoran ternak dengan ketebalan 15-20 cm; (3) Tambahkan arang sekam dan serbuk gergaji di atas kotoran ternak; (4) Buat larutan MOL dengan takaran 2,5 liter MOL dan 10 loter air kemudian diaduk hingga MOL larut; (5) Campurkan larutan MOL ke kotoran ternak sedikit demi sedikit sembari diaduk hingga rata; (6) Tutupi campuran dengan terpal atau plastik dan tunggu hingga 3-5 hari kemudian bongkar dan aduk kembali hingga rata; (7) Setelah 10 hari, pupuk siap digunakan dengan ciri-ciri tidak panas ketika dikepal dan berbentuk remahan.

\section{Pelatihan pembuatan pestisida organik.}

Pelatihan ini bertujuan untuk warga yayasan "Cahaya Alam" mengetahui arti pentingnya dan manfaat pestisida organik disertai dengan praktik pembuatan pestisida organik dari bahan bahan di lingkungan sekitar yayasan "Cahaya Alam" seperti daun pepaya, daun pahitan, daun sirzat, daun sirih, dan daun-daun lain yang mengandung minyak atsiri.

Langkah pembuatan teknologi pestisida nabati adalah: (1) Siapkan daun pepaya, daun mindi, atau daun sirsak sebanyak $1 \mathrm{~kg}$; (2) Blender seluruh daun kemudian saring untuk mendapat airnya; (3) Campurkan air sari daun dengan deterjen $30 \mathrm{gr}$ dan air 10 liter kemudian aduk rata dan diamkan semalaman; (4) Pestisida siap digunakan.

\section{Pembuatan demplot sayuran organik}

Pelatihan ini bertujuan agar warga yayasan "Cahaya Alam" mengetahui arti pentingnya bercocok tanam sayuran organik disertai dengan praktik membuat demplot sayuran organik dan penanaman bunga hias. Pengumpulan data dilakukan selama 3 bulan sejak Juni 2020 hingga September 2020. Metode pengumpulan data adalah metode survei. Data yang diperoleh adalah data primer dan data sekunder. Data primer diperoleh melalui Focus Group Discussion (FGD) dan wawancara langsung kepada ketua yayasan "Cahaya Alam". Pengambilan sampel sebanyak 30 responden anggota yayasan yang menanam sayuran organik. 
ABDIMAS: Jurnal Pengabdian Masyarakat Universitas Merdeka Malang

Volume 6, No. 2, May 2021: 186-195

Untuk keberlanjutan pembinaan diperlukan praktik yang secara terus menerus. Metode evaluasi meliputi teknik pengumpulan data yang dilakukan dengan pre-test dan post-test. Durasi kegiatan dilakukan selama 3 bulan.

Penggunaan kuisioner dilakukan untuk menilai keberhasilan dalam kegiatan pelatihan peningkatkan pengetahuan dan pemahaman petani mengenai budidaya sayuran organik, PHT, cara pembuatan, dan aplikasi pestisida nabati serta pupuk organik. Hasil evaluasi menunjukkan yayasan "Cahaya Alam" menjadi terampil dalam membuat pupuk organik dan pestisida nabati dari bahan-bahan yang terdapat di sekitar lahan yayasan (Yazid, 2013). Indikasi keberlanjutan program pengabdian ini akan dilakukan survei pretest dan post-test setelah dilakukan pendidikan masyarakat, pelatihan, pendampingan, introduksi alat dan hasil yang diperoleh dari penerapan edukasi pertanian organik.

\section{HASIL DAN PEMBAHASAN}

Program pengabdian masyarakat tentang edukasi pertanian organik untuk budidaya sayuran dan bunga hias di Yayasan "Cahaya Alam" Desa Kucur, Kecamatan Dau, Kabupaten Malang secara umum telah berlangsung dengan baik. Adapun kegiatan pengabdian ini sudah terlaksana berdasarkan target luaran yaitu: (1) Jasa pendidikan masyarakat dan pelatihan edukasi pertanian organik dengan pemanfaatan lahan untuk budidaya sayuran dan bunga hias, masing-masing minimal 3 kali; (2) Jasa pendampingan kepada warga yayasan "Cahaya Alam" yang menerapkan pertanian organik untuk budidaya sayur dan bunga hias dengan pemupukan organik dan pembuatan MOL minimal 1 bulan; 3) Pelatihan pembuatan pestisida organik minimal 1 kali.

\section{Pelatihan budidaya sayuran organik}

Pelatihan yang dilakukan telah meningkatkan pengetahuan dan pemahaman petani tentang edukasi pertanian organik untuk sayuran dan kebun bergizi seperti sayuran sawi, selada, kacang panjang, cabai kecil, cabai besar, dan tomat (Kastanja et al., 2019). Selain itu, pelatihan tentang cara pembuatan pupuk organik yang melibatkan para anggota yayasan secara aktif mulai dari penyediaan bahan, persiapan bahan, dan pembuatan pupuk organik telah mampu meningkatkan pengetahuan dan keterampilan anggota mitra dalam pembuatan pupuk organik dan pestisida nabati. Sebagian besar anggota yayasan juga sudah mengetahui bahan-bahan apa saja yang dapat digunakan dalam pembuatan pupuk organik.

Berdasarkan hasil pengamatan pada masing-masing pelatihan edukasi tanaman sayuran sawi, selada, kacang panjang, cabai kecil, cabai besar, dan tomat di lahan mitra yayasan "Cahaya Alam". Terlihat bahwa kondisi pertumbuhan tanaman terlihat baik dengan penambahan pupuk organik yang dibuat dengan penambahan stater dari MOL. Formulasi pupuk organik MOL yang dibuat dapat berperan ganda baik sebagai pupuk maupun sebagai pengendali hama. Hama yang ditemukan pada tanaman sawi, selada, dan kacang panjang organik adalah Crocidolomia binotalis dan Plutella xylostella (Tuhuteru et al., 2019). Larutan MOL mengandung unsur hara makro dan mikro yang juga mengandung bakteri yang berpotensi sebagai perombak bahan organik, perangsang pertumbuhan, dan sebagai agen pengendali penyakit. 


\section{Edukasi Budidaya Sayuran dan Bunga Hias Organik pada Yayasan “Cahaya Alam” Desa Kucur Kota Malang \\ Eny Dyah Yuniwati, Umi Afdah}

Hasil dari pelatihan pembuatan MOL dari nasi basi dan campuran larutan gula ini berguna sebagai stater dalam pembuatan pupuk organik dari bahan kompos di sekitar pondok yayasan "Cahaya Alam". Menurut Selviana (2019), dengan memberikan MOL pada proses fermentasi pupuk kompos akan membuat pupuk kompos matang lebih cepat sehingga bisa segera digunakan.
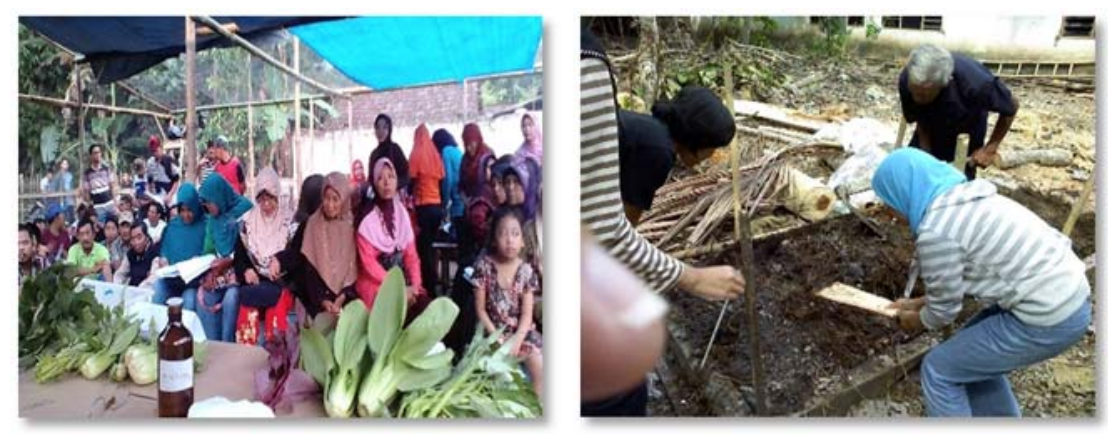

Gambar 1. Pelatihan edukasi sayur organik dan pembuatan pupuk organik kompos

\section{Pelatihan pembuatan pupuk organik}

Hasil pelatihan menunjukkan antusias warga pondok yayasan "Cahaya Alam" dalam edukasi sayuran organik dan praktik dalam pembuatan pupuk komposnya. Pupuk kompos ini sangat diperlukan sebagai tambahan unsur hara dalam budidaya sayuran organik baik di demplot maupun di polybag (Tabun et al., 2017; Kardinan, 2011).

Keunggulan dari pupuk organik adalah: (1) Meningkatkan kemampuan mengikat unsur hara; (2) Memperbaiki struktur tanah; (3) Meningkatkan serapan air, kelembaban dan aerasi tanah; (4) Molekul organik mampu mengurangi tokisitas logam dan pestisida.

Setelah kurang lebih 3 bulan, hasil sayuran bisa dipanen terutama sawi, selada, dan tomat. Hasil panen dapat dirasakan warga pondok yayasan "Cahaya Alam" untuk dikonsumsi maupun dijual. Manfaat dari edukasi ini selain hasil panen sayurannya sehat juga dapat memperoleh hasil dari penjualannya yang dapat digunakan untuk memenuhi ekonomi pondok yayasan terutama untuk biaya pendidikan anakanak dan kesehatan. Setiap panen, rata-rata hasil yang diperoleh sebanyak Rp498.000. Tetapi perolehan ini tidak bisa stabil karena harga penjualan sayur-sayuran sangat fluktuatif.

Tabel 1 menunjukkan jenis sayuran, hasil panen, dan hasil pendapatan dalam edukasi sayuran organik di yayasan "cahaya alam".

Tabel 1. Jenis sayuran, hasil panen, dan hasil pendapatan edukasi sayuran organik di yayasan "Cahaya Alam"

\begin{tabular}{lrr}
\hline \multicolumn{1}{c}{ Jenis sayuran } & Hasil panen & Hasil penjualan (Rp) \\
\hline Sawi & $20 \mathrm{~kg}$ & 50.000 \\
Selada & $15 \mathrm{~kg}$ & 75.000 \\
Kacang panjang & $10 \mathrm{~kg}$ & 10.000 \\
Cabai rawit & $5 \mathrm{~kg}$ & 105.000 \\
Cabai besar & $7 \mathrm{~kg}$ & 210.000 \\
Tomat & $10 \mathrm{~kg}$ & 48.000 \\
Total rerata per panen & & 498.000 \\
\hline
\end{tabular}


ABDIMAS: Jurnal Pengabdian Masyarakat Universitas Merdeka Malang

Volume 6, No. 2, May 2021: 186-195

\section{Media tanam polybag dan demplot}

Penanaman sayuran organik seperti, sawi, selada, kacang panjang, cabai rawit, dan cabai besar dilakukan di lahan dengan cara membuat demplot (Yazid, 2013), sedangkan penanaman tomat dapat dilakukan di polybag dengan tujuan agar morfologi dari tomat tidak banyak yang rusak dan roboh.
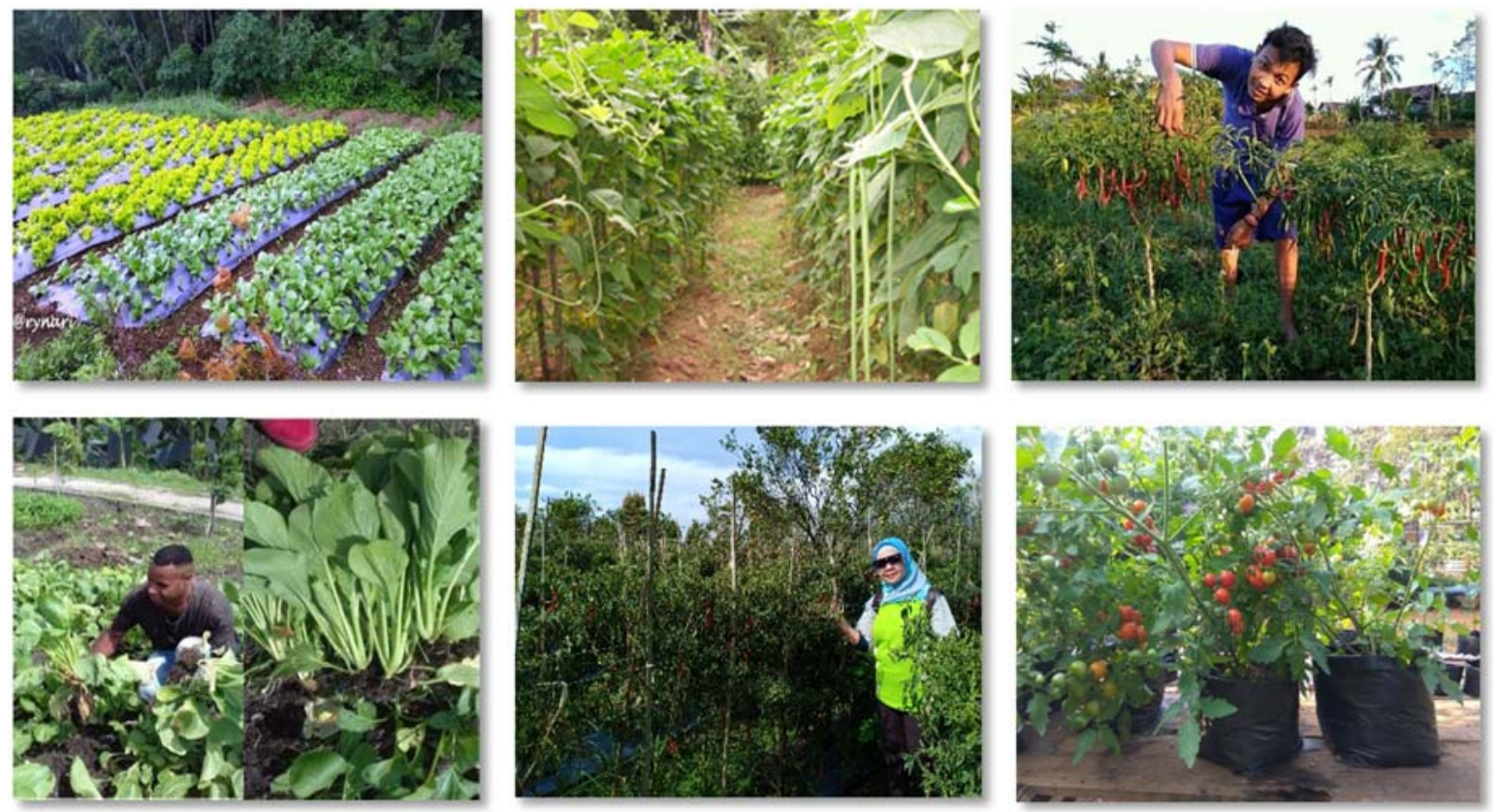

Gambar 2. Demplot sawi, selada, kacang panjang, cabai rawit, cabai besar, dan tomat di polybag

\section{Pembangunan Screen house}

Screen house terbuat dari bahan kayu dengan penutup plastik sebagai atapnya. Fungsi dari screen house adalah untuk menjaga kondisi pembibitan tanaman di dalam screen house supaya suhu dan kelembabannya stabil. Hal ini dilakukan karena kondisi cuaca di luar screen house sangat heterogen dan dapat mempengaruhi pertumbuhan serta perkembangan tanaman (Kuncoro \& Wijaya, 2019). Di dalam screen house dapat dilakukan pembibitan untuk sayuran organik dan bunga hias.
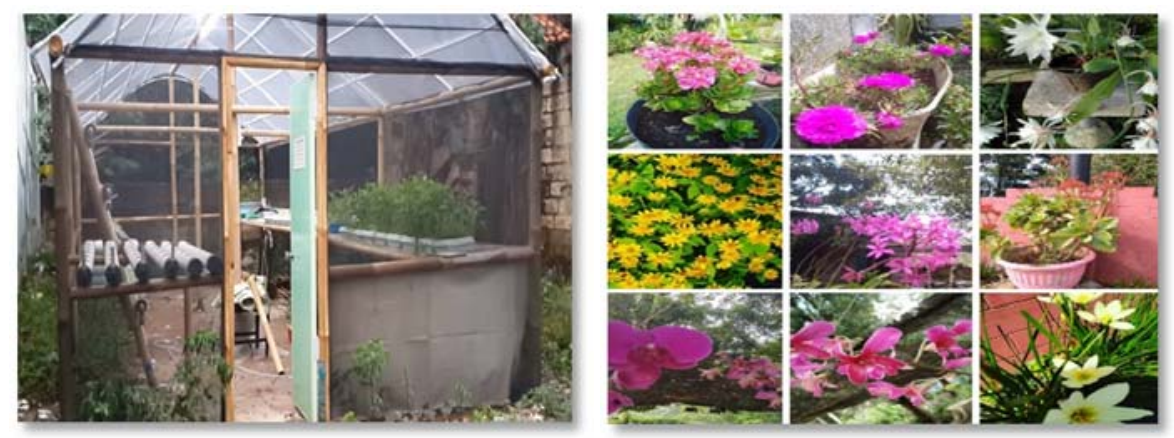

Gambar 3. pembangunan screen house untuk pembibitan dari sayuran yang akan di tanam dan koleksi tanaman hias yayasan "Cahaya Alam" 


\section{Edukasi Budidaya Sayuran dan Bunga Hias Organik pada Yayasan “Cahaya Alam” Desa Kucur Kota Malang}

Eny Dyah Yuniwati, Umi Afdah

\section{Pelatihan pestisida nabati}

Pestisida nabati adalah pestisida yang bahan aktifnya bersumber dari tumbuh-tumbuhan, seperti akar, daun, batang, atau buah. Menurut Supartha et al. (2012), pestisida digunakan untuk mengendalikan hama dan penyakit yang biasa menyerang pada tumbuhan. Bahan dari tumbuhan biasanya diolah menjadi berbagai bentuk, seperti tepung dan ekstrak seperti ekstrak dari daun pepaya, tembakau, biji mahoni, dan sebagainya. Pestisida nabati cocok untuk segala tanaman perkebunan, holtikultura, padi, dan palawija karena sifatnya yang tidak beracun dan tidak menimbulkan pencemaran baik udara maupun lingkungan disekitar.

Manfaat pestisida nabati adalah: (1) Tidak mencemari lingkungan (ramah lingkungan) karena mudah terurai (biodegradable) di alam; (2) Relatif aman bagi manusia dan ternak karena residunya mudah hilang; (3) Dapat membunuh hama atau penyakit; (4) Sebagai pengumpul atau perangkap hama tanaman orok-orok dari kotoran ayam; (5) Bahan yang digunakan nilainya murah serta tidak sulit dijumpai dari sumber daya yang ada di sekitar dan bisa dibuat sendiri; (6) Mengatasi kesulitan ketersediaan dan mahalnya harga obat-obatan pertanian khususnya pestisida sintetis atau kimiawi; (7) Walau penggunaan dalam dosis tinggi sekalipun tanaman sangat jarang ditemukan mati.

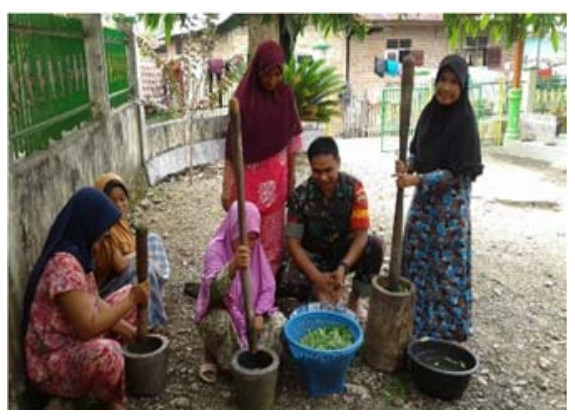

Gambar 4. Ibu-ibu membuat pestisida organik dengan cara ditumbuk

\section{Pendampingan}

Pendampingan dilakukan langsung oleh tim pelaksana dan beberapa pembantu teknis lapang dari mahasiswa. Pendampingan dilakukan dalam bentuk pengarahan teknis aplikasi edukasi pertanian organik untuk sayuran organik, toga, dan bunga hias pada yayasan "Cahaya Alam". Pendampingan ini dilakukan agar mitra mengenal proses edukasi pertanian organik.

Tabel 2. Perbandingan sebelum dan sesudah pelatihan Edukasi Pertanian organik di yayasan "Cahaya Alam"

\begin{tabular}{lcc}
\hline \multicolumn{1}{c}{ Jenis Pelatihan } & Sebelum pelatihan (skor) & Sesudah pelatihan (skor) \\
\hline Pendidikan masyarakat dan Sosialisasi Edukasi pertanian & 1 & 4 \\
organik & 1 & 4 \\
Pelatihan pembuatan MOL & 1 & 4 \\
Pelatihan Aplikasi MOL dalam pembuatan pupuk kompos & 1 & 3 \\
Pelatihan pembuatan pestisida organik & 2 & 4 \\
Pembuatan demplot sayuran organik & 2 & \\
\hline
\end{tabular}

Keterangan skor penilaian: 1 = belum mengerti; 2 = cukup mengerti; 3 = jelas mengerti; 4 = sudah melaksanakan 
ABDIMAS: Jurnal Pengabdian Masyarakat Universitas Merdeka Malang

Volume 6, No. 2, May 2021: 186-195

\section{SIMPULAN DAN SARAN}

Kegiatan pengabdian masyarakat edukasi pertanian organik untuk budidaya sayuran organik, di yayasan "Cahaya Alam" Desa Kucur, Kecamatan Dau, Malang merupakan bentuk realisasi dari sebuah konsep pemberdayaan pertanian organik yang berguna dan berkontribusi dalam visi pengembangan pertanian organik. Di dalam kegiatan pengabdian ini juga terdapat pelatihan dan penerapan teknologi pertanian organik yaitu pupuk organik, MOL, dan pestisida organik. Guna keberlanjutan dari sebuah program pengabdian ini, tim pendamping berusaha untuk mengkolaborasikan antara mitra yayasan "Cahaya Alam" dengan kepala Desa Kucur agar praktik edukasi sayuran organik dapat saling bersinergis. Selain melakukan pendampingan di bidang produksi, tim pengabdi juga melakukan pendampingan pasar dan proses pemasaran. Hal ini dilakukan guna mencukupi kebutuhan masyarakat secara ekonomi. Dari evaluasi dan analisis program pengabdian masyarakat yang telah dilakukan maka dapat disimpulkan sebagai berikut: (1) Yayasan "Cahaya Alam" sangat mendukung dan antusias untuk mengembangkan edukasi pertanian organik, khususnya sayuran organik dan bunga hias; (2) Berdasarkan hasil respondensi, mitra merasa mudah bertani organik; (3) Program pengabdian dapat meningkatkan wawasan, pengetahuan, dan keterampilan dalam pemanfaatan lahan sehingga menjadi lebih produktif; (4) Edukasi pertanian organik berhasil meningkatkan hasil produksi sayuran organik dan meningkatkan perekonomian; (5) Pemberdayaan masyarakat harus dilakukan secara komprehensif dengan melibatkan berbagai unsur dan dilakukan secara berkelanjutan dengan implementasi berbagai bidang.

Setelah melakukan program pengabdian edukasi ini, masih ada keterbatasan-keterbatasan antara lain, dalam melaksanakan program edukasi ini diperlukan persiapan antar pihak, pengabdi, dan mitra agar program bisa berjalan dengan baik. Bagi pengabdi selanjutnya diperlukan pengembangan dari program edukasi sayuran organik dan tanaman hias lanjutan untuk pemberdayaan ekonomi di mitra. Diperlukan program lanjutan yang berhubungan dengan pengolahan pasca produk dan pemasarannya.

\section{Ucapan Terima Kasih}

Ucapan terima kasih ditujukan kepada yayasan "'Cahaya Alam"" dan Universitas Wisnuwardhana yang telah terlibat dalam pengabdian masyarakat ini dan pihak masyarakat yang telah membantu melaksanakan pengabdian masyarakat.

\section{Daftar Pustaka}

Kardinan, A. (2011). Penggunaan pestisida nabati sebagai kearifan lokal dalam pengendalian hama tanaman menuju sistem pertanian organik. Pengembangan Inovasi Pertanian, 4(4), 262-278.

Kastanja, A. Y., Patty, Z., \& Dilago, Z. (2019). Pelatihan budidaya sayuran organik di Desa Daru Kecamatan Kao Utara. Jurnal Pengabdian Masyarakat Multidisiplin, 2(3), 186-195. https://doi.org/10.36341/jpm.v2i3.798

Kuncoro, P. H., \& Wijaya, K. (2019). Peningkatan pemahaman dan minat warga Desa Serang Kabupaten Purbalingga terhadap teknologi screen-house dan sistem hidroponik untuk memperkuat budidaya strawberry. Dimas Budi Jurnal Pengabdian kepada Masyarakat, 3(1), 28-33. 
Nasir, B., Najamudin, N., Lakani, I., Lasmini, S. A., \& Sabariyah, S. (2020). Pembuatan pupuk organik cair dan biofungisida trichoderma untuk mendukung sistem pertanian organik. Jurnal Penelitian dan Pengabdian kepada Masyarakat UNSIQ, 7(2), 115-120.

https://doi.org/10.32699/ppkm.v7i2.756

Purba, M. D. O. (2016). Analisis Tingkat Partisipasi Petani Dalam Kegiatan Budidaya Sayuran Organik Di Cv Kurnia Kitri Ayu Farm Malang. Universitas Brawijaya.

Selviana, T. E. (2019). Pengolahan Limbah Nasi Basi menjadi Pupuk Organik Cair Mikroorganisme Lokal (MOL) bagi Tanaman. https://doi.org/10.31219/osf.io/snbdv

Supartha, I. N. Y., Wijana, G., \& Adnyana, G. M. (2012). Aplikasi jenis pupuk organik pada tanaman padi sistem pertanian organik. E-Jurnal Agroekoteknologi Tropika, 1(2), 98-106.

Tabun, A. C., Ndoen, B., Leo-Penu, C. L. O., Jermias, J. A., Foenay, T. A. Y., \& Ndolu, D. A. J. (2017). Pemanfaatan limbah dalam produksi pupuk bokhasi dan pupuk cair organik di Desa Tuatuka Kecamatan Kupang Timur. JPMP: Jurnal Pengabdian Masyarakat Peternakan, 2(2), 107-115. http://dx.doi.org/10.35726/jpmp.v2i2.212

Tuhuteru, S., Mahanani, A. U., \& Rumbiak, R. E. Y. (2019). Pembuatan pestisida nabati untuk mengendalikan hama dan penyakit pada tanaman sayuran di Distrik Siepkosi Kabupaten Jayawijaya. JPKM: Jurnal Pengabdian kepada Masyarakat, 25(3), 135-143.

https://doi.org/10.24114/jpkm.v25i3.14806

Yazid, M. (2013). Pemberdayaan petani melalui introduksi teknologi pembuatan dan aplikasi pestisida nabati pada demplot sayuran organik di Kelurahan Talang Keramat Kabupaten Banyuasin. Jurnal Pengabdian Sriwijaya, 1(2), 50-56. https://doi.org/10.37061/jps.v1i2.1550 